\title{
Balarısı (Apis mellifera) Zehirinin, Kobayda Tansiyona ve Barsak Hareketlerine Etkisi
}

The Effects of Honeybee (Apis mellifera) Venom on the Blood Pressure and the Infestinal Motility of the Guinea-pig

Orhan ALTINKURT*

Melih ALTAN*

\section{GiRiş}

Arı sokması sonucu görülen semptomlar genellikle vücuda giren zehir miktarına bağlıdır. Normal arı sokmalarında şişlik, ağrı ve kızarıklık gibi birkaç saat içinde kaybolan geçici, lokal etkiler oluşur. Çok sayıda arının sokması ya da çocuklarda görülebileceği gibi vücut ağırlığına, tek arının bile zehirinin fazla isabeti sonucu daha ciddi semptomlar ve ölüm görülebilir. Söz konusu semptomlar arasında bulant, kusma, lakrimasyon, sfinkter gevşemesi, dyspnea, konvülsiyon, trismus gibi nörotoksik ve nöromuskuler etkiler belirtilmiştir (1).

Balarısı (Apis mellifera) zehiri, çeşitli arıların zehirleri arasında farmakolojik etkilerin incelenmesi açısından uygun bir örnektir. Elektriksel stimülasyon ya da zehir kesesinin serum fizyolojik ile ekstraksiyonu sonucu elde edilen ham zehir, vücuda girme yerinde ağrı, irritasyon, ödem, hemoliz, çizgili ve düz kas kontraksiyonu şeklinde lokal ve metabolik etkilere ek olarak kalb durması gibi sonuçlar da doğurabilir. Zehir etkisiyle sistemik arter basıncında başlangıçtaki yükselişten sonra belirgin bir hipotansif etki izlenir. Ayrıca Santral Sinir Sisteminde eksitasyon da belirtilmiştir. Bizim çalışmamızda Ankara çevresinden toplanan balarılarının kobay arter basıncı ve kobay ileumu üzerindeki etkileri incelenmiştir.

Redaksiyona verildiği tarih: 17 Mart 1978.

* Farmakoloji Kürsüsü, Eczacılık Fakültesi, Ankara Üniversitesi. 


\section{MATERYAL ve YÖNTEM}

Satın alınan kovandaki arıların öldürülmesinden sonra herbirinin zehir taşıyan kuyruk kısımları vücuttan ayrılmıştır. Kuyruklar kurutulup havanda ezildikten sonra kuyruk başına $1 \mathrm{cc}$. olmak üzere serum fizyolojik ile ekstre edilmiştir. 24 saat soğukta bekletilip santrifüj edilmiş ve kullanılmak için supernatant ayrilmıştır.

1. Tansiyon Deneyleri: Bunun için, dişi ve erkek olmak üzere her iki cinsten 400-700 g, arasında sağlıklı kobaylar seçilerek kullanılmıştır. Kobaylar $1.25 \mathrm{~g} / \mathrm{kg}$. urethane ile anesteziye edildikten sonra A. carotis ve V. jugularis'leri disseke edilmiştir. Sol taraftaki A. carotis'e konan kanül aracılığıyla alınan basınç Statham kan basinç Transducer'i ile Schwarzer Poligrafinda kaydedilmiştir. Ml. de 50 ü.i. Heparin kapsayan serum fizyolojik ve diğer enjeksiyonlar V. jugularis yoluyla yapılmıştır.

2. Düz Kas Üzerindeki Deneyler: Bununla ilgili çalışmalar kobay terminal ileumunda yapılmıştır. 400-600 g. ağırlı̆ındaki kobaylar öldürüldükten sonra karın bölgesi hemen açılarak ileo-çekal sfinkter'e en yakın kısımdan alınan $2-3 \mathrm{~cm}$. uzunluğundaki parçalar mezenterden arındırılarak kullanılmıştır. İleum $10 \mathrm{cc}$. lik banyoda $37^{\circ} \mathrm{C}$ de $\% 95 \mathrm{O}_{2}$ ve $\% 5 \mathrm{CO}_{2}$ karışımı ile satüre edilmiş Tyrode solüsyonunda, 1 saat bekletildikten sonra deneye başlanmıştır. Kayıtlar bir frontal lövye ile kimografa yazdırılmıştır. Arı zehir ekstresi üzerindeki antagonistik etkiler kümülatif doz-cevap eğrileri (2) kullanılarak incelenmiştir. Her parça için önce an zehiri ekstresi ile kümülatif doz-cevap eğrisi elde edildikten sonra deneye başlanmıştır. Kobay ileumu antagonist ile 2 dakika inkübasyona brrakılmış, sonra antagonist varlığında arı zehiri ekstresi ile yeniden kümülatif doz-cevap eğrisi çıkarılmıştır. Her parçada yalnız bir antagonist doz denenmiş her konsantrasyon için yeni bir parça kullanılmıştır.

\section{Deneyde Kullanılan Maddeler:}

Histamine $\mathrm{SO}_{4}$ (Merck)

Arı Zehiri Ekstresi (A.Z.)

Heparin

(Mustafa Nevzat, İstanbul 5000 ü. i/cc) 
Systral

Antistamin

(İbrahim Ethem, İstanbul $10 \mathrm{mg}$ Klorfenoksamin $\mathrm{HCI} / \mathrm{cc}$ )

(Mustafa Nevzat, İstanbul $10 \mathrm{mg} \quad \beta$ dimethyl aminoethyl-4-methyl benzhydryl eter $\mathrm{HCI} / \mathrm{cc}$ )

\section{BULGULAR}

1. Zehirin Tansiyona Etkisi: Kobayda; $0.2 \mathrm{cc} / \mathrm{kg}, 0.4 \mathrm{cc} / \mathrm{kg}$, $0.8 \mathrm{cc} / \mathrm{kg}$ dozlarında zehir ekstresi I.V verildikten sonra arter basincında bir düşme saptanmıştır. (Şekil 1). Başlangıçtaki kısa süreli bu düşmeden sonra tansiyonun hemen normale dönmesine karşın bazan da bu hipotansif etkiyi yaklaşı olarak 10-15 dakika süren hipertansif bir etkinin izlediği gözlenmiştir (Şekil 2).

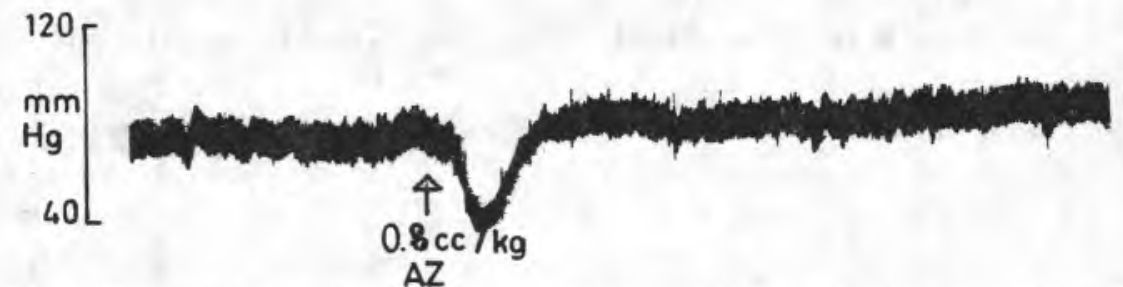

Şek. 1. Urethan anestezisi altındaki kobayın kan basıncında arı zehirinden sonra izlenen düş̧me

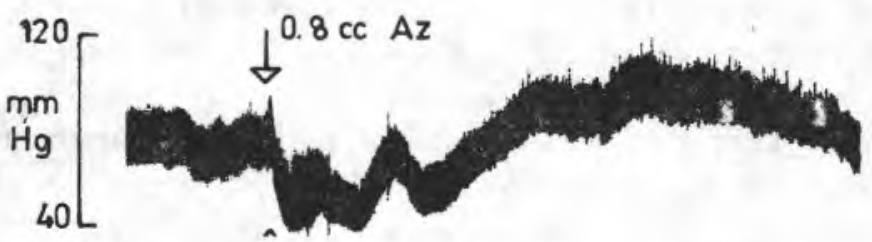

Şek. 2. Kobay kan basıncında arı zehirinin hipotansif etki:ini izleyen hipertansif etki.

I.V verilen $0.2 \mathrm{cc} / \mathrm{kg}, 0.4 \mathrm{cc} / \mathrm{kg}, 0.8 \mathrm{cc} / \mathrm{kg}$ arı zehiri ekstresinden sonra arter basıncındaki düşmeler Tablo 1 de görülmektedir.

Arı zehirinin başlangıçtaki tansiyon düşürücü etkisinin, zehirden 15 dakika önce, bir antihistaminik ilaç olan Systral'in I.V verilme- 
Tablo I. (Ortalama \pm Standart Hata)

\begin{tabular}{|c|c|c|}
\hline $0.2 \mathrm{cc} / \mathrm{kg}$ & $0.4 \mathrm{cc} / \mathrm{kg}$ & $0.8 \mathrm{cc} / \mathrm{kg}$ \\
\hline Kobay Arter Basıncı $12.15_{ \pm 0} 0.89$ & $\begin{array}{c}17.48_{ \pm} 0.77 \\
(12)\end{array}$ & $\begin{array}{c}22.85_{ \pm} 1.23 \\
(10)\end{array}$ \\
\hline
\end{tabular}

Parantez içindeki rakamlar deney sayısııı göstermektedir.

siyle azaldığı saptanmıştır (Şekil 3 A,B; 4 A,B; 5 A,B), Systral'in bu antagonistik etkisi kompetitif bir şekilde oluşmuştur.

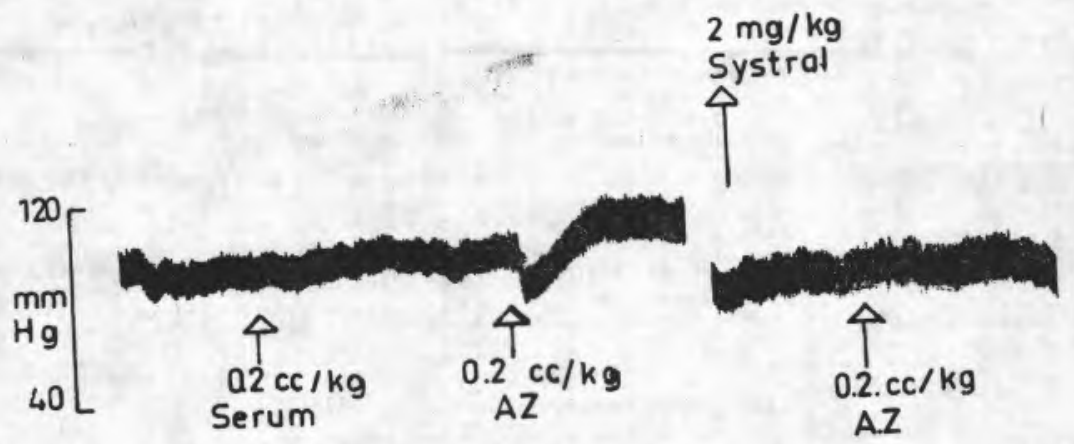

Sek. 3A $0.2 \mathrm{cc} / \mathrm{kg}$ Arı zehirinin kobay kan basıncı üzerine etkisi
Şek. 3B. $2 \mathrm{mg} / \mathrm{kg}$ Systral'den sonra arı zehirinin kan basıncı üzerine etkisi.

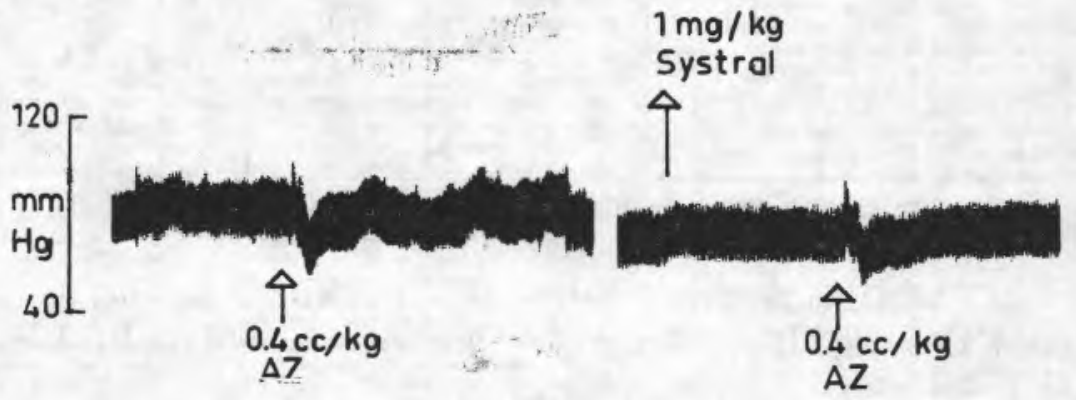

Șek. 4A. $0.4 \mathrm{cc} / \mathrm{kg}$ arı zehirinin kobay kan basıncı üzerine etkisi.
Șek. 4B. $1 \mathrm{mg} / \mathrm{kg}$ Systral'den sonra arı zehiririnin kobay kan basıncı üzerine etkisi. 

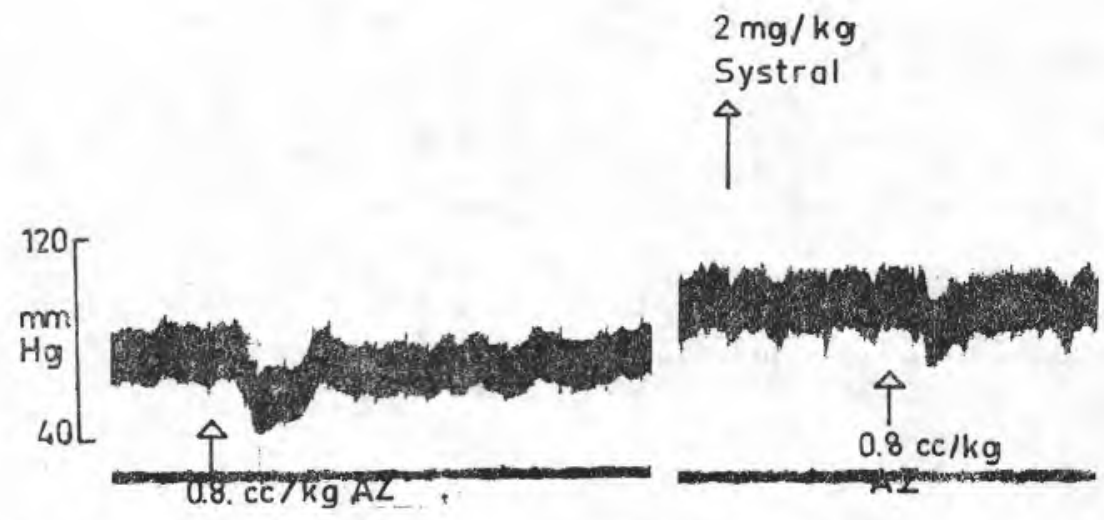

Sek. 5A. $0.8 \mathrm{cc} / \mathrm{kg}$ arı zehirinin kobay kan basincı üzerine etkisi

Şek. 5B. $2 \mathrm{mg} / \mathrm{kg}$ Systral'den sonra arı zehirinin kobay kan basıncı üzerine etkisi

Tablo 2 ve Tablo 3 de $1 \mathrm{mg} / \mathrm{kg}$ ve $2 \mathrm{mg} / \mathrm{kg}$ Systral'den sonra arı zehiri ekstresi ile kan basıncındaki düşmeler görülmektedir.

Tablo II. (Ortalama $\mp$ Standart Hata)

\begin{tabular}{|c|c|c|}
\hline $0.2 \mathrm{cc} / \mathrm{kg}$ & $0.4 \mathrm{cc} / \mathrm{kg}$ & $0.8 \mathrm{cc} / \mathrm{kg}$ \\
\hline Kobay Arter Basincı $4.78 \mp 0.75$ & $\begin{array}{c}8.95 \mp 1.15 \\
(6)\end{array}$ & $\begin{array}{c}13.71 \mp 1.2 \\
(7)\end{array}$ \\
\hline
\end{tabular}

Parantez içindeki rakamlar deney sayısını göstermektedir.

Tablo III. (Ortalama \pm Standart Hata)

\begin{tabular}{|c|c|c|}
\hline $0.2 \mathrm{cc} / \mathrm{kg}$ & $0.4 \mathrm{cc} / \mathrm{kg}$ & $0.8 \mathrm{cc} / \mathrm{kg}$ \\
\hline Kobay Arter Basincı 0 & $4.45 \underset{+}{(6)} 0.55$ & $10.07 \div 1.1$ \\
$(7)$ & $(8)$ & \\
\hline
\end{tabular}

Parantez içindeki rakamlar deney sayısını göstermektedir.

(Şekil 6) da arı zehiri ekstresinin kobay arter basıncındaki dozcevap eğrisi görülmektedir. Şekilde de görüldüğü gibi eğriler, kontrol ile paraleldirler.

Aynı sonucun histogram ile ifadesi Şekil 6A'da gösterilmiştir.

2. Zehirin Kobay Illeumuna Etkisi: Hazırladı̆̆ımız zehir ekstresi kobay ileumu üzerinde konstriktör bir etki göstermiştir. Ancak ileumun arı zehirine olan cevabı antihistaminik etkili bir diğer ilaç 


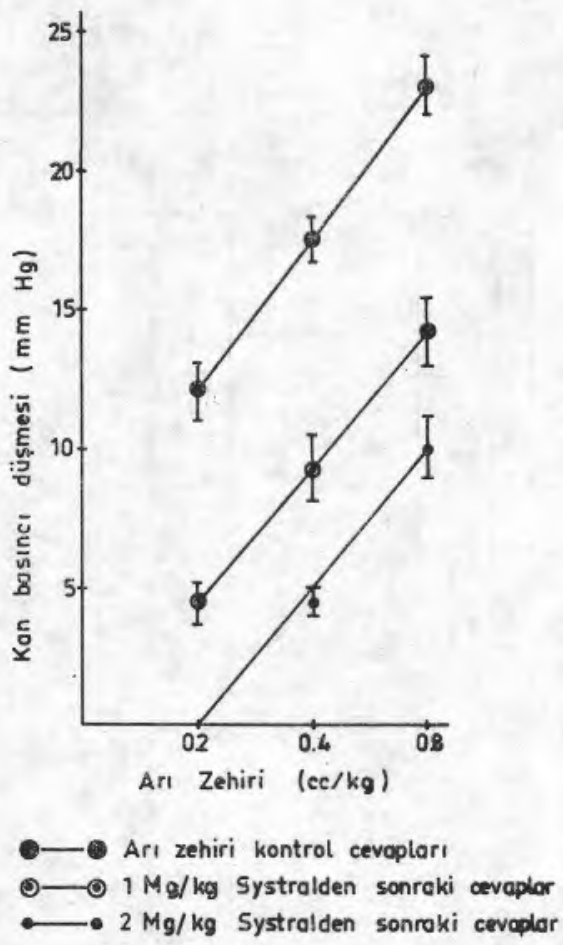

Şek. 6. Arı zenırinin kobay arter basıncı üzerindeki doz-cevap eğrisi

olan Antistamin'den sonra azalmıştır (Şekil 7). Antistamin'in arı zehirine karşı olan antagonistik etkisi nonkompetitif bir şekilde oluşmuştur. (Şekil 8) de arı zehir ekstresinin kobay ileumu üzerindeki kümülatif doz-cevap eğrisi görülmektedir. Arter basıncındaki hipotansif etkiyi antagonize eden Systral, antikolinerjik etkili olması nedeni ile barsakta antagonist olarak kullanılmamıs, yerine Antistamin kullanılmıştır.

TARTIŞMA ve SONUÇ

Modern teknikler kullanılarak yapılan araştırmalar, balarısı zehirinde toksik ve farmakolojik etkili maddelerin varhı̆ını ortaya koymuştur. 


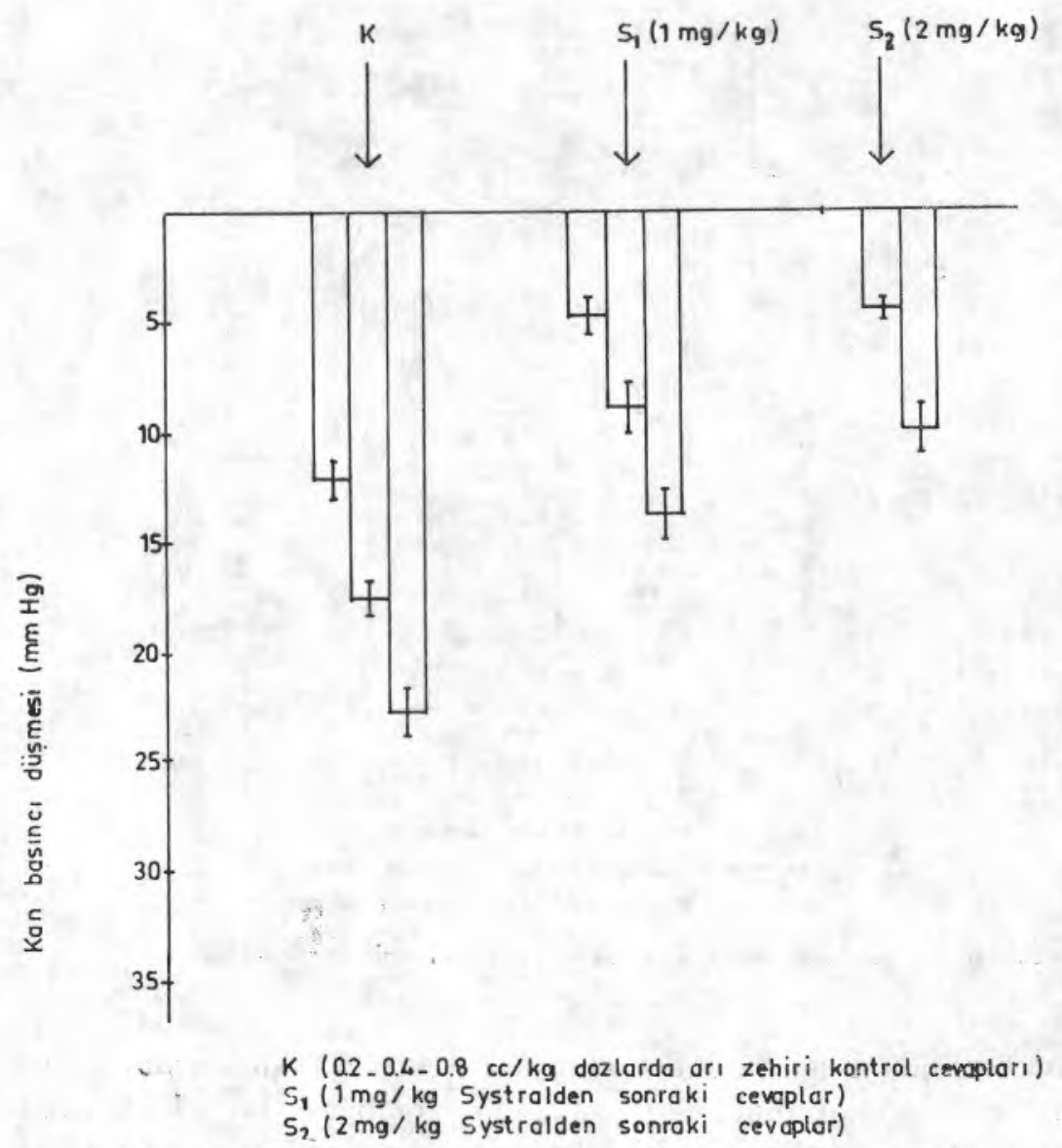

Şek. 6A. Arı zehirinin kobay arter basıncı üzerindeki doz-cevap eğrisinin histogram ile ifadesi.

Arı zehirinin nörotoksik etkilerini bir polipeptid olan ve kuru zehirde $\% 2$; zehir ekstresinde ise $\% 0.2$ oranında bulunan Apamin adlı maddenin oluşturduğu bilinmektedir (3).

Zehirin asll toksik komponenti ise gene bir polipeptid olan ve kuru zehirde $\%$ 40-50, zehir ekstresinde ise $\%$ 4-5 oranında bulunan hemolitik etkili Mellitin'dir. (4). Kobay ileumunda kontraksiyon, izole siçan diyaframında sinaptik iletim blokajı ve trombositlerden serotonin liberasyonu da Mellitin'in bildirilen etkileri arasındadır (5). 

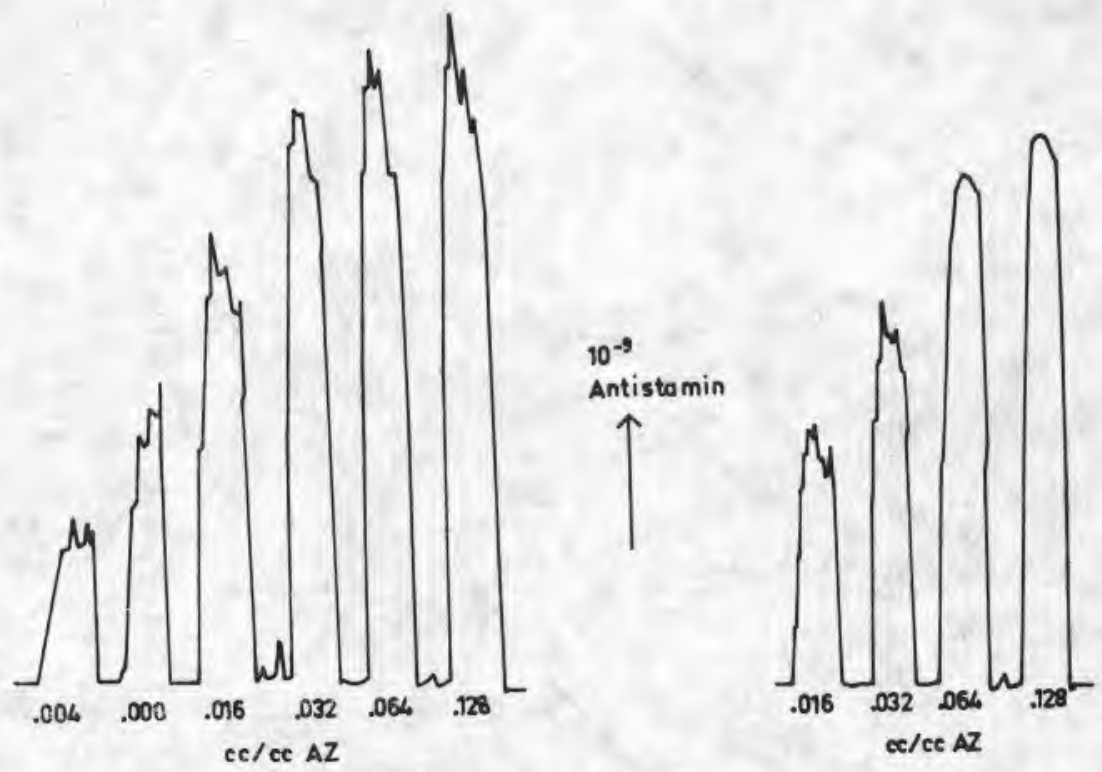

Şek. 7. Arı zehirinin kobay ileumu üzerindeki etkisi

Anesteziye tavşanda Mellitin'in kısa süreli bir hipotansif etki oluşturduğu gözlenmiştir (6). Gene anesteziye kedide yapılan çalışmalarda Mellitinin vertebral artere verilişinden sonra tansiyon yükselmiştir. Ancak arter basıncında oluşan yükselmeden önce kısa süreli bir hipotansiyon saptanmıs, daha sonra ise yükselen basınç giderek şok düzeyine kadar düşmüştür. Mellitin anesteziye hayvanlara vena femoralis yolu ile verildiğinde, kan basıncı üzerindeki etkilerinin daha hafif olduğu; önce bir yükselme ya da düşme saptandığı, yinelenen dozlarda ise tansiyonun genellikle düştüğü belirtilmiştir (7).

Mellitin'in vertebral artere verilişinden sonra kedi arter basınconda gösterdiği bifazik etkiye benzer etki, akrep zehirinin çeşitli hayvanlara I.V verilmesinden sonra da saptanmıştır. Bu zehirin kedi, köpek ve tavşanlarda oluşturduğu uzun süreli hipertansif etkiden önce çok kısa süren, hafif bir hipotansiyon gözlenmiş ve bu da Atropin ile giderilmiştir (8).

Bizim çalışmamızda, arı zehirinin başlangıçta gösterdiği hipotansif etki atropinle önlenememiş olduğundan, etkinin acetylcholline'- 


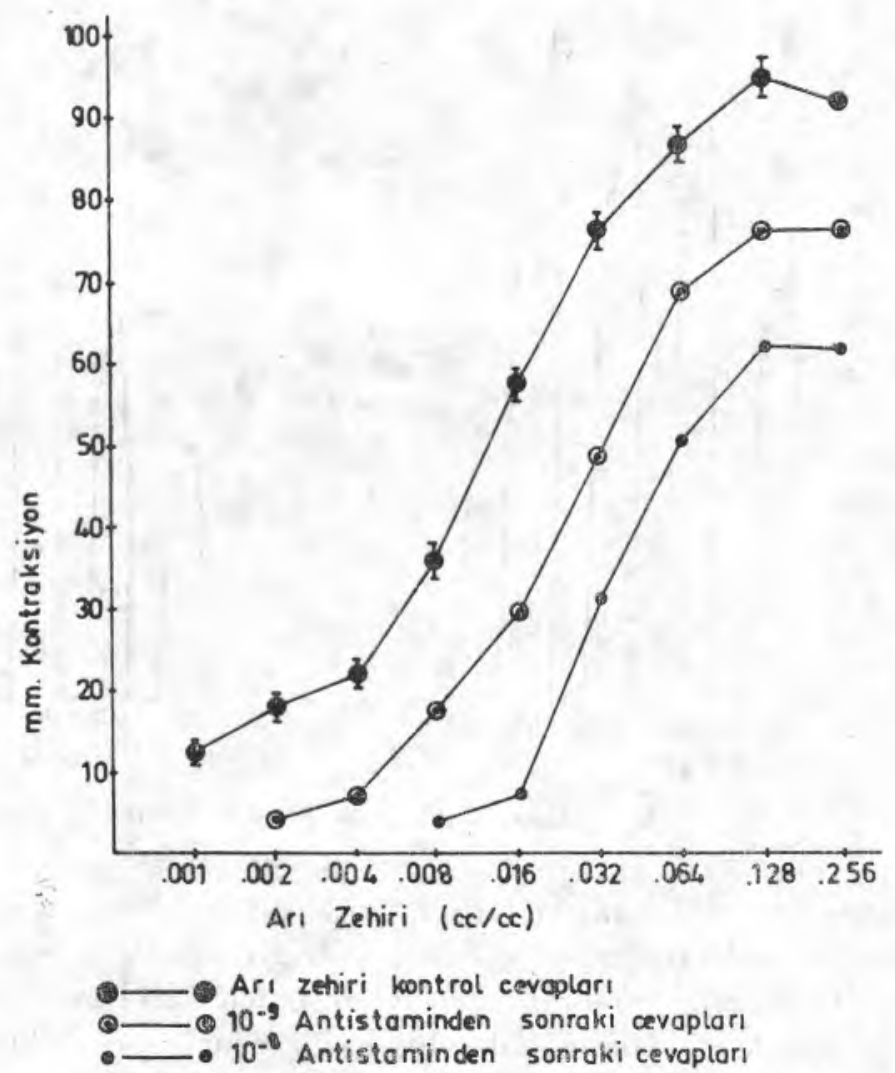

Şek. 8. Arı zehirinin kobay ileumu üzerindeki doz-cevap eğrisi

den ileri gelebileceği yaklaşımı giderilmiştir. Ancak bu etkinin ya zehirin kapsadığı histaminden (9) ya da zehirin içerdiği Mellitin'in histamin liberatörü rol oynayarak histamin deşarjı yaptırmasından oluşabileceği varsayımı, çalışmamızda Systral'den sonra etkinin azaltılması ile kanıtlanmıştır. Yaptığımız kromatografik incelemede Arı zehir ekstresinde histamin varlığı görülmektedir. (Krom. 1) Zaten Mellitin'in sıçan mast hücrelerinden histamin açığa çıkmasına neden olduğu da bilinmektedir (4).

Arı zehirinin kobay ileumu üzerindeki konstriktör etkisi ise gene antihistaminik bir ilaç olan Antistamin'in $10^{-8}$ ve $10^{-9}$ konsantrasyonlarında inhibe edilmiştir. Bu inhibisyonun, arter basıncında sapta- 


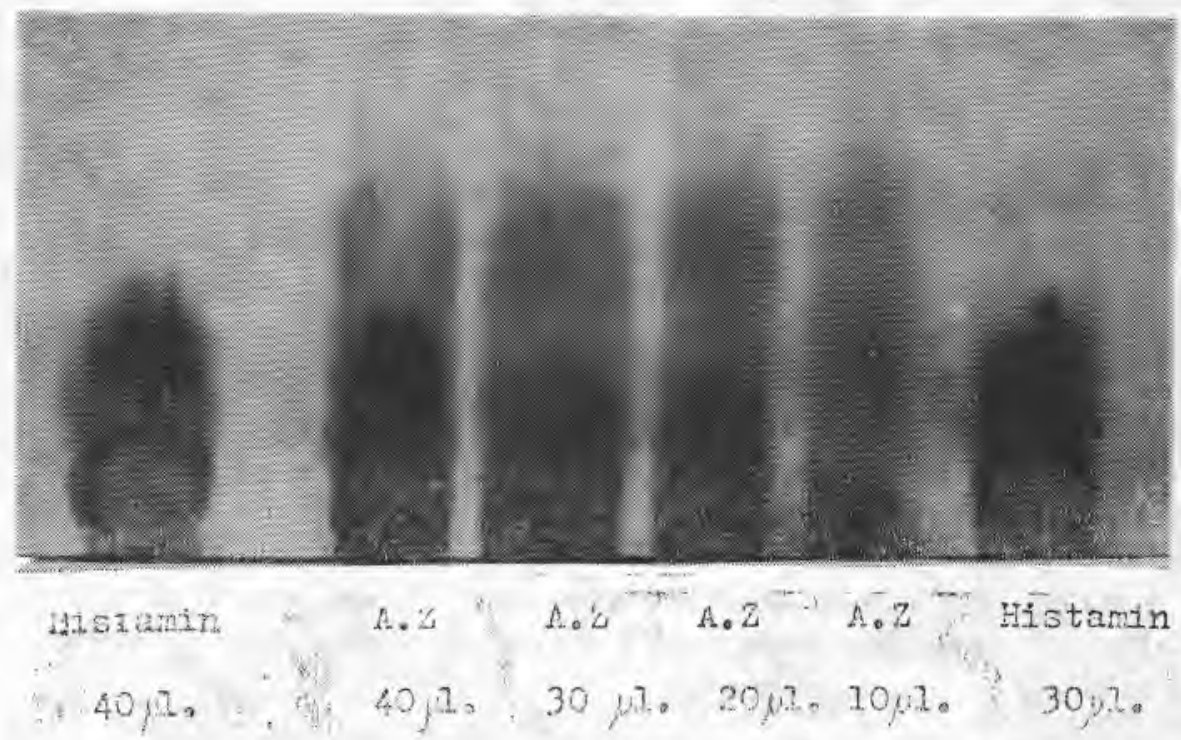

Krom. 1. Arr zehiri ekstresi kromatogramı. (Histamin $10^{-3} \mathrm{M}$ stok solusyondan kullazulmıștır)

nan kompetitif antagonizmanin tersine nonkompetitif bir tipte oluşması, zehirin kastırıcı etkisinin yalnızca histaminden ileri gelmediğini, histamin ve mellitin ile serotonin veya başka maddelerin birlikte etkimesinden oluşabileceğini düşündürmektedir $(5,6)$.

ÖZET

Ankara çevresi arılarından elde edilen zehir ekstresi I.V verildiğinde kobay arter basıncında kısa süreli hıpotansif etki oluşturmakta ve çoğunlukla tansiyon hemen normale dönmektedir. Bazan da bu hipotansif etkiyi, akrep zehirinin çeşitli laboratuvar hayvanlarında meydana getirdiği, önce hipotansiyon sonra hipertansiyon yaptırıcı etkisindeki gibi, 10-15 dakika süren bir hipertansiyon izlemektedir. Akrep zehirinde atropinle giderildiği bilinen, arı zehirinde ise atropinle önleyemediğimiz bu hipotansif etki Systral ile kompetitif bir şekilde antagonize edilmektedir.

Arı zehiri ekstresi kobay ileumunda kastırıcı bir etki göstermekte ve bu etki de Antistamin ile inhibe edilmektedir. Fakat buradaki etki, tansiyondakinden farklı olarak nonkompetitifdir. 


\section{SUMMARY}

The venom extract obtained from the honeybees of the Ankara environment, given intravenously, produced a short-lived hypotension on the guinea-pig blood pressure. Usually the blood pressure was returned to its normal level in a short time. Sometimes this hypotensive effect was followed by a hypertension which lasted for 10 or 15 minutes. Similar effects had been reported by several investigators with scorpion venom on several laboratory animals. Although this initial hypotensive effect produced by the scorpion venom could be prevented with atropine, the same effect of the bee venom could not be blocked with it. However, Systral antagonized this hypotensive effect competitively. The bee venom extract constricted the guineapig ileum and this action of the extract was inhibited with Antistamin. But this antagonism is different from the effect on the blood pressure as being a noncompetitive one.

\section{LITERATÚR}

1. Phisalix, M., -Animaux Venimeux et venins. Masson ad Cie, Paris, France (1922).

2. Rossum, J.M. van and Brink, G van den., -Arch. Int. Pharmacodyn. Thếr., 143, 240246 (1963).

3. Habermann, E.,-Recent studies on Hymenoptera venom, In: Recent Advances in the Pharmacology of Toxins, Proc. 2nd Int. Pharmac. Meeting. p. 53 New York: Pergamon Press. (1965).

4. Habermann, E., -Bee and wasp venoms. Science, 177, 314. (1972).

5. Diniz, C.R., Corrado, A.P., -Venoms of insects and arachinids. International Encyclopedia of Pharmacology and Therapeutics. Section 71 Volume 11 (1971).

6. Habermann, E. and Zeuner, G., -Comparative studies of native and synthetic Mellitins. Naunyn-Schmiedebergs Arch. Pharmak. 270, 1-9 (1971).

7. Ishay, J., Ben-Shachar, D., Elazar, $\mathbf{Z}$ and Kaplinsky, E., -Effects of Mellitin on the Central Nervous System. Toxicon, Vol 13, pp. 277-283 (1975).

8. Corrado, A.P., Riccioppo Neto, F and Antonio, A., - The mechanism of the hypertensive effect of Brazilian scorpion venom (Tityus serrulatus Lutz e Mello) Toxicon, 12, 145 (1974).

9. Russell, F. E., -Comparative pharmacology of some animal toxins. Fed. Proc., 26, 120624 (1967). 